\title{
Support for hybrid models of the age of acquisition of English nouns
}

\author{
JAMIE REILLY \\ University of Florida, Gainesville, Florida \\ Evangelia G. Chrysikou \\ University of Pennsylvania, Philadelphia, Pennsylvania \\ AND \\ Christopher H. RAMEY \\ Florida Southern College, Lakeland, Florida
}

\begin{abstract}
Age of acquisition (AoA) is a psycholinguistic construct that refers to the chronological age at which a given word is acquired. Contemporary theories of AoA have focused on lexical acquisition with respect to either the developing phonological or semantic systems. One way of testing the relative dominance of phonological or semantic contributions is through open-source psycholinguistic databases, whereby AoA may be correlated with other variables (e.g., morphology, semantics, phonology). We report two multiple regression analyses conducted on a corpus of English nouns with, respectively, subjective and objective AoA measures as the dependent variables and a combination of 10 predictors, including 2 semantic, 4 phonological, 2 morphological, and 2 lexical. This multivariate combination of predictors accounted for significant proportions of the variance of AoA in both analyses. We argue that this evidence supports hybrid models of language development that integrate multiple levels of processing - from sound to meaning.
\end{abstract}

Word learning involves three overarching mechanisms: the processing and retention of an arbitrary, symbolic lexical-phonological representation; the formation of a stable conceptual representation; and the mapping between a lexical representation and a concept (Aslin, Saffran, \& Newport, 1998; Paivio, 1986). These mechanisms are moderated by many other psycholinguistic variables, including a word's grammatical class (Gentner, 1982) and morphological complexity (R. W. Brown, 1976), as well as intrinsic factors such as theory of mind (Bloom, Margulis, Tinker, \& Fujita, 1996). Language acquisition research has focused extensively on each of these domains in relative isolation, with the rationale that one can identify the unique contribution of a given psycholinguistic construct to the variance of another by controlling for the first's effects. With this additive paradigm, although multiple variables are being accounted for, they are methodologically isolated and treated independently. A more global understanding of the complex relations among these factors, therefore, represents a major challenge for language acquisition research. One potentially fruitful way to examine such relations is through the use of open-source psycholinguistic databases. In the present study, we examined a large corpus of English nouns with subjective age of acquisition (AoA) norms obtained from the Cambridge psycholinguistic database (Coltheart,
1981), as well as a smaller corpus of nouns with objective AoA norms obtained from Morrison, Chappell, and Ellis (1997), in order to determine the relative importance of various psycholinguistic factors contributing to English noun acquisition.

Lexical acquisition variability has been examined through a variety of experimental and naturalistic means, including diary studies of production, preferential lookingtime comprehension tasks, and standardized school-based vocabulary assessments. Language researchers have operationalized chronological variability in lexical acquisition as a discrete psycholinguistic variable-namely, AoA. It can be manipulated and controlled for in a task just as other psycholinguistic variables are, such as word frequency, word length, or concreteness (for a review, see Juhasz, 2005). Nevertheless, the validity of AoA as an independent psycholinguistic variable is controversial because of how AoA values have been obtained. The largest corpora of values were derived through adults' retrospective estimation of when they acquired a word or concept (Bird, Franklin, \& Howard, 2001; Gilhooly \& Logie, 1980). Even though this technique relies on remote source memory, adult subjective AoA ratings correlate strongly with more objective methods of obtaining AoA. For example, Morrison et al. (1997; see also Morrison, Hirsh, Chappell, \& Ellis, 2002) reported a small set of objective

J.Reilly, jjreilly@phhp.ufl.edu 
AoA norms $(N=297$ words $)$ derived from picture naming. The correlation between these objective norms and the Gilhooly and Logie (1980) adult subjective ratings was $r=.75$. A second source of converging evidence for the validity of subjective AoA norms comes from a longitudinal study of vocabulary acquisition, comparing childhood subjective ratings at ages 9 and 11 with adult subjective AoA norms. Adults' subjective ratings correlated strongly with children's $(r=.82)$. In addition, children's subjective ratings correlated with actual acquisition as measured by observational records of when words were first spoken or read $(r=.71$ for speech and $r=.77$ for text; see Zevin \& Seidenberg, 2002; see also Funnell, Hughes, \& Woodcock, 2006). Thus, subjective AoA norms appear to provide a valid and robust measure of an important factor in lexical acquisition. ${ }^{1}$

The AoA construct has received much attention in the psycholinguistic literature recently because of effects attributed to AoA in the language processing of adults (e.g., speeded naming and lexical decision latencies; see Juhasz, 2005). Similarly to a word frequency effect, in which words more frequent in a language are more rapidly processed (Jescheniak \& Levelt, 1994), AoA effects include more efficient processing of earlier acquired material.

Juhasz (2005) has identified five competing theories regarding the etiology of AoA effects, two of which provide the anchors to a spectrum from pure phonological to pure conceptual-semantic processing explanations. Proponents of the phonological completeness hypothesis have argued that AoA effects emerge primarily as a result of early limitations in articulatory processing that resolve with maturity (G. D. Brown \& Watson, 1987; Morrison \& Ellis, 2000). Later acquired words tend to be longer, and are composed of less probable phonotactic sequences that are difficult for a very young child to produce. Therefore, an exclusively phonological account of AoA reflects limitations in variables such as phonological encoding, motor speech development, and articulatory planning. These factors regard the locus of variability in lexical acquisition within the output-production system. In contrast, proponents of a semantic locus hypothesis have suggested that AoA is moderated by the accrual of semantic knowledge based on associations with earlier learned words (Brysbaert, Lange, \& Van Wijnendaele, 2000; Steyvers $\&$ Tenenbaum, 2005). Abstract words (e.g., love) are acquired later because their representations are based on an associative network of previously acquired concrete words (e.g., mom, ice cream, dog, blanket). Thus, AoA effects may reflect the gradual emergence of semantic networks necessary to support abstract lexical concepts (see also Paivio, 1985). This approach is consistent with connectionist models of word processing that represent abstract and concrete words through qualitatively different means, either through verbally mediated associations or more direct perceptual representation (e.g., Nelson \& Schreiber, 1992; Paivio, 1986).

A wealth of psycholinguistic data is available regarding phonological and semantic variables that are likely to influence AoA (e.g., frequency, imageability, phonotactic probability). It is surprising, then, that studies have thus far not taken greater advantage of these data to evaluate the pure phonological and pure conceptual-semantic processing explanations of AoA. The examination of such variables in large databases has the potential to reveal complexities methodologically and statistically unavailable to previous investigations. As an example, consider the necessarily bivariate correlations between AoA with a semantic variable (e.g., imageability) and with a phonological variable (e.g., word length). The correlation (Pearson's $r$ ) between AoA and imageability values for a large set of English nouns $(N=2,877)$ is $r=-.67$ (see Reilly \& Kean, 2007). That is, there is a strong negative linear relationship between a semantic property and AoA, consistent with a semantic locus hypothesis; concrete nouns (e.g., $d o g$ ) are acquired earlier in life than are abstract nouns (e.g., truth). In contrast, there is a positive linear correlation $(r=.56)$ between this set of AoA values and word lengths measured in phonemes per word (a phonological property), supporting a phonological completeness hypothesis wherein shorter words (e.g., cat) are acquired earlier than are longer words (e.g., catastrophe).

In isolation, these correlations, and the theories their proponents may support, do not address the complex relationships between phonological and semantic components, relationships that reject an exclusively semantic or phonological account of AoA. We argue that parsing the variance of AoA can be accomplished by means of multivariate regression analyses that treat AoA as an outcome variable, as opposed to a predictor, as is common in previous research (see Juhasz, 2005). That is, rather than use AoA as a variable to predict, for example, reaction times to stimuli, the present article identifies those psycholinguistic variables that contribute to AoA. This type of analysis is valuable because it may reveal relations between linguistic components that are not available through behavioral approaches focusing exclusively on these components in isolation. Furthermore, an additional advantage of a regression approach to AoA is that it may add to our understanding of lexical acquisition from a developmental perspective (i.e., what factors contribute to the psycholinguistic construct of AoA diachronically). In the sections that follow, we report two multivariate regression analyses of an array of phonological, lexical, and semantic variables toward AoA.

\section{MULTIVARIATE ANALYSIS FOR SUBJECTIVE AOA MEASURES}

\section{Construction of Noun Corpus}

In order to assemble a large corpus of nouns for AoA prediction, we first acquired all English nouns with imageability values from the Medical Research Council (MRC) psycholinguistic database (Coltheart, 1981, www.psych .rl.ac.uk). Items were then cross-referenced with the $O x$ ford English Dictionary (Simpson \& Weiner, 1989), and those labeled obscure, colloquial, rare, poetical, or dialectal were eliminated. A further exclusion criterion referred to noun homophones whose written frequency value was dominated by an alternate syntactic category. That is, an item's frequency as a noun was contrasted to its frequency 
as a member of an alternate syntactic category. A ratio of greater than 5:1 (noun:other) was used as a cutoff criterion to ensure that entries were pure nouns (Kučera \& Francis, 1982). This exclusionary measure primarily affected nouns that function more commonly as verbs (e.g., look, must, know). However, a small number of nouns that function as modifiers (e.g., tweed, blue) were also eliminated. The final result of these inclusion criteria was a corpus of 2,877 nouns, coded for the following characteristics.

Age of acquisition. AoA values for each noun were obtained from the Gilhooly and Logie (1980) adult subjective rating norms, as renormed in the MRC database. AoA values were scaled to a 100-700-point range following the formula: AoA rating $(100 \times 1[0-2$ yrs] to 7 [13 on]; $\mu=405 ; \sigma=120$, range $=125-697$; for the normative procedure, see Coltheart, 1981).

Word familiarity. Word familiarity values were obtained from the MRC norms (Coltheart, 1981; Gilhooly \& Logie; 1980; Paivio, Yuille, \& Madigan, 1968; Toglia $\&$ Battig, 1978). Familiarity values were scaled to a range of $100-700(\mu=488, \sigma=99)$.

Imageability. Imageability has been defined as the extent to which a word rapidly evokes a strong mental image (Barca, Burani, \& Arduino, 2002). For example, dog is rated as highly imageable, whereas imageability ratings for truth are lower, indicating something more abstract. The MRC database acts as a pool for merging three of the most widely utilized imageability data sets in psycholinguistic research. These include the Gilhooly and Logie (1980), Paivio (Paivio et al., 1968), and Toglia and Battig norms (Toglia \& Battig, 1978). Imageability ratings of these separate data sets were rescaled to form a continuous distribution with values that range from 100 (least imageable) to 700 (most imageable) $(\mu=456, \sigma=108)$.

Word length in syllables. Entries were coded for word length in total syllables.

Consonant clustering. Individual syllables were also coded using a categorical measure of phonologically simple or complex; simple structures were operationalized as being free of consonant clusters. A measure of phonological complexity was derived by calculating the total number of complex syllables per word.

Morphology/derivational complexity. Derivational complexity was coded by counting total word stems, prefixes, and suffixes.

Compounding. Rate of compounding was also coded as a separate categorical independent variable. Compound words (e.g., fireplace, bulldog, catfish) were coded as monomorphemic rather than treating one component as a prefix or suffix (for the rationale, see R. W. Brown, 1976).

Etymology/word origin. Noun origin was first traced to its earliest known entry in the English language (Oxford English Dictionary, 1989). All entries were then grouped into the five most commonly occurring etymologies across the data set (i.e., Germanic, Latinate, Greek, unknown, other).

Phonological neighborhood density. The phonological neighborhood for a word is made up of the set of words that differ from a target by only the substitution, addition, or omission of one phoneme (Luce \& Pisoni, 1998; see also Jusczyk, Luce, \& Charles-Luce, 1994). For example, a phonological neighborhood for the target cat would include neighbors such as sat, at, cot, and cap. Neighborhood density values for all nouns were obtained from the Washington University Speech and Hearing Laboratory (128.252.27.56/neighborhood/Home.asp).

Primary stress. Entries were nominally coded for primary syllable stress (e.g., whískey vs. guitár). Coding was completed for words greater than one syllable and less than six syllables in length.

Word frequency. Measures of word frequency were obtained for each item from a large database of hypertext frequency (Lund \& Burgess, 1996) obtained from the English Lexicon Project (elexicon.wustl.edu; Balota et al., 2007).

Correlational analyses between variables among nouns in the present corpus $(N=2,877)$ demonstrated lexical, phonological, and semantic relations with AoA (see also Reilly \& Kean, 2007). ${ }^{2}$

\section{Results}

Preparation for multiple regression analysis. The above-mentioned characteristics were hypothesized to contribute to a word's AoA to various degrees. To investigate this hypothesis, a standard multiple regression was performed with AoA as the dependent variable and with the following predictors: familiarity, imageability, syllables per word, number of consonant clusters per word, morphemes per word, compounding, word etymology, phonological neighborhood density, written frequency (log hypertext), and stress. AoA norms were available for 1,381 of the original 2,877 nouns from the MRC database; thus, only entries with corresponding AoA values were included in the analysis.

Prior to analysis, all of the variables were examined by means of various programs provided in the Statistical Package for the Social Sciences (SPSS) for accuracy of data entry, missing values, and fit between the distributions of each variable and the assumptions of multivariate analysis. The results of the evaluation of assumptions did not reveal any violation of linearity and homoscedasticity, and no significant violations of normality were observed for any of the variables. The assumptions of multicollinearity and singularity were also satisfied. ${ }^{3}$ No missing values were identified for any of the variables, and no univariate outliers were observed; however, following the criterion of Mahalanobis distance, 30 cases were found to be multivariate outliers with $p<.001$. All outliers were deleted, leaving 1,351 cases for analysis. The ratio of cases to the number of independent variables was satisfactory (minimum number of cases required $N=812$ for the detection of a small effect, $f^{2}=.01$; Tabachnick \& Fidell, 2001).

Results of multiple regression analysis. Table 1 displays the correlations between the variables, the unstandardized regression coefficients $(B)$ and intercept, the standardized regression coefficients $(\beta)$, the semipartial correlations $\left(s r_{\mathrm{i}}^{2}\right), R^{2}$, and adjusted $R^{2}$. The regression model fits the data well $[F(10,1340)=422.96, p<.001$, mean square residual $=3,059.84]$. For the eight regression coefficients that differed significantly from zero, $95 \%$ confidence intervals for $B$ were calculated. The significance of these factors was confirmed by the lack of in- 
Table 1

Standard Multiple Regression of Noun Characteristics on Subjective Measures of Age of Acquisition $(N=1,351)$

\begin{tabular}{|c|c|c|c|c|c|c|c|c|c|c|c|c|c|c|}
\hline Variables & AoA & FAM & IMAG & NSYL & NCONC & NMRPH & COMP & ETYM & DENS & STRS & HFRQ & $B$ & $\beta$ & $s r^{2}$ \\
\hline FAM & -.63 & & & & & & & & & & & $-.75^{* *}$ & -.50 & .11 \\
\hline IMAG & -.68 & .26 & & & & & & & & & & $-.45^{* *}$ & -.39 & .10 \\
\hline NSYL & .57 & -.21 & -.43 & & & & & & & & & $21.60^{* *}$ & .21 & .01 \\
\hline NCONC & .13 & -.04 & -.15 & -.03 & & & & & & & & $7.13^{*}$ & .04 & $<.01$ \\
\hline NMRPH & .45 & -.18 & -.42 & .67 & .07 & & & & & & & -.52 & -.003 & \\
\hline COMP & -.06 & -.01 & .11 & .03 & .01 & -.07 & & & & & & -18.81 & -.02 & \\
\hline ETYM & -.27 & .06 & .27 & -.31 & -.08 & -.23 & .05 & & & & & $-3.31^{*}$ & -.03 & $<.01$ \\
\hline DENS & -.47 & .19 & .34 & -.61 & -.22 & -.36 & -.10 & .28 & & & & $-1.32^{* *}$ & -.10 & $<.01$ \\
\hline STRS & .41 & -.10 & -.35 & .63 & .05 & .51 & -.07 & -.18 & -.30 & & & $10.93^{* *}$ & .06 & $<.01$ \\
\hline HFRQ & -.37 & .69 & .04 & -.21 & -.04 & -.19 & -.12 & .01 & .18 & -.13 & & $3.39^{*}$ & .05 & $<.01$ \\
\hline & & & & & & & & & & & & \multicolumn{3}{|c|}{ Intercept $=913.50$} \\
\hline Means & 406.47 & 494.44 & 473.73 & 2.13 & .46 & 1.36 & 0.2 & N/A & 5.93 & 1.27 & 8.78 & & & \\
\hline \multirow[t]{2}{*}{$S D \mathrm{~s}$} & 112.36 & 74.16 & 96.86 & 1.09 & .56 & .65 & .15 & N/A & 8.32 & .59 & 1.65 & & & \\
\hline & & & & & & & & & & & & \multicolumn{3}{|c|}{$\begin{array}{l}R^{2}=.76_{\mathrm{a}} \\
\text { Adjusted } R^{2}=.76 \\
R=.87^{* *}\end{array}$} \\
\hline
\end{tabular}

Note-A unique variability, .24; shared variability, .52. AoA, subjective age of acquisition; FAM, familiarity; IMAG, imageability; NSYL, number of syllables; NCONC, number of consonant clusters; NMRPH, number of morphemes; COMP, number of compound clusters; ETYM, etymology; DENS, phonological neighborhood density; STRS, stress; HFRQ, $\log$ of hypertext frequency; $S D$, standard deviation. $\quad{ }^{*} p<.05 . \quad{ }^{* *} p<.01$.

clusion of zero as a possible value for the $95 \%$ confidence intervals for each variable.

Eight of the 10 independent variables contributed significantly to AoA: etymology $\left(s r_{\mathrm{i}}^{2}<.01\right)$, familiarity $\left(s r_{\mathrm{i}}^{2}=\right.$ $.11),(\log )$ hypertext frequency $\left(s r_{\mathrm{i}}^{2}<.01\right)$, imageability $\left(s r_{\mathrm{i}}^{2}=.10\right)$, phonological neighborhood density $\left(s r_{\mathrm{i}}^{2}=\right.$ $.01)$, number of consonant clusters $\left(s r_{\mathrm{i}}^{2}<.01\right)$, number of syllables $\left(s r_{\mathrm{i}}^{2}=.01\right)$, and word stress $\left(s r_{\mathrm{i}}^{2}<.01\right)$. The eight independent variables, in combination, contributed another $52 \%$ in shared variability. All together, 76\% (and $76 \%$ adjusted) of the variability in AoA was predicted by knowing the characteristics of a word on these eight variables.

Although the correlations between AoA and rate of compounding $(r=.06, p=.02)$ and number of morphemes $(r=.45, p<.001)$ were significant, these variables did not contribute significantly to the regression. Post hoc evaluations revealed that the correlations were significant for both compounding $[F(10,1340)=7.23, p<.01]$ and for the number of morphemes $[F(10,1340)=110.97$, $p<.001]$. It appears that the relationships between AoA and these factors are mediated by the relationships between AoA and etymology, familiarity, (log) hypertext frequency, imageability, number of syllables, number of consonant clusters, phonological neighborhood density, and word stress.

\section{MULTIVARIATE ANALYSIS FOR OBJECTIVE AOA MEASURES}

\section{Construction of Noun Corpus}

The multiple regression on the subjective AoA measures suggested that a combination of phonological, morphological, and semantic factors significantly predicts AoA. However, despite the reported high correlations between subjective and objective AoA measures (see, e.g., Morrison et al., 1997), it is possible that these factors function as significant predictors for only subjective AoA. To examine whether a similar combination of predictors would account for the variability for objective AoA, we examined the significance of the above-mentioned 10 factors in predicting objective AoA measures as reported by Morrison et al. (1997). For 168 of the 297 nouns for which Morrison et al. obtained objective AoA measures, scores on the 10 psycholinguistic characteristics, including subjective AoA ratings, were also available from the larger corpus used in the previous analysis. The correlation between subjective and objective AoA for the 168 nouns was significant $(r=.51, p<.001)$.

\section{Results}

Preparation for multiple regression analysis. Given the results of the regression analysis on the subjective AoA measures, a standard multiple regression was performed with objective AoA as the dependent variable and the same 10 predictors. Following the procedures used in the initial analysis, the results of the evaluation of multivariate assumptions did not reveal any significant violations, and no missing values or univariate outliers were identified. Following the criterion of Mahalanobis distance, 18 cases were found to be multivariate outliers with $p<.001$. All outliers were deleted, leaving 150 cases for analysis. The ratio of cases to the number of independent variables was satisfactory (minimum number of cases required $N=64$ for the detection of a medium effect, $f^{2}=.15$; Tabachnick \& Fidell, 2001).

Results of multiple regression analysis. Table 2 displays the correlations between the variables, the unstandardized regression coefficients $(B)$ and intercept, the standardized regression coefficients $(\beta)$, the semipartial correlations $\left(s r_{\mathrm{i}}^{2}\right), R^{2}$, and adjusted $R^{2}$. The rate of compounding did not vary in the present smaller corpus; hence, this factor was removed from the analysis. The regression model fits the data well $[F(9,140)=5.40, p<.001$, mean square residual $=400.26]$. For the three regression coefficients that differed significantly from zero, 95\% confidence intervals for $B$ were calculated. The significance of these factors was confirmed by the lack of inclusion of zero as a possible value for the $95 \%$ confidence intervals for each variable. 
Table 2

Standard Multiple Regression of Noun Characteristics on Objective Measures of Age of Acquisition $(N=150)$

\begin{tabular}{|c|c|c|c|c|c|c|c|c|c|c|c|c|c|}
\hline Variables & AoA & FAM & IMAG & NSYL & NCONC & NMRPH & ETYM & DENS & STRS & HFRQ & $B$ & $\beta$ & $s r^{2}$ \\
\hline$\overline{\text { FAM }}$ & -.42 & & & & & & & & & & $-.10^{*}$ & -.24 & .03 \\
\hline IMAG & -.02 & .13 & & & & & & & & & $<.01$ & .01 & \\
\hline NSYL & .12 & -.25 & .09 & & & & & & & & -7.79 & -.22 & \\
\hline NCONC & -.01 & -.04 & $<.01$ & -.30 & & & & & & & -7.90 & -.17 & \\
\hline NMRPH & $<.01$ & -.01 & -.04 & .07 & -.06 & & & & & & -11.57 & -.04 & \\
\hline ETYM & .02 & -.04 & .03 & .03 & .05 & .15 & & & & & .71 & .03 & \\
\hline DENS & -.22 & .26 & -.04 & -.63 & -.22 & -.06 & $<.01$ & & & & $-.64^{*}$ & -.27 & .03 \\
\hline STRS & .01 & $<.01$ & .07 & .39 & -.02 & -.02 & -.01 & -.25 & & & -.31 & $<.01$ & \\
\hline HFRQ & -.43 & .59 & -.05 & -.24 & -.05 & -.07 & -.01 & .25 & -.11 & & $-4.78^{* *}$ & -.28 & .05 \\
\hline & & & 50290 & & & & & & & & \multicolumn{2}{|c|}{ Intercept $=167.94$} & \\
\hline \multirow[t]{2}{*}{$S D \mathrm{~s}$} & $\begin{array}{l}45.63 \\
22.51\end{array}$ & $\begin{array}{r}328.13 \\
55.88\end{array}$ & $\begin{array}{r}592.99 \\
29.34\end{array}$ & $\begin{array}{l}1.46 \\
0.64\end{array}$ & $\begin{array}{r}.33 \\
0.47\end{array}$ & $\begin{array}{l}1.01 \\
0.08\end{array}$ & $\begin{array}{l}\text { N/A } \\
\text { N/A }\end{array}$ & $\begin{array}{r}11.48 \\
9.55\end{array}$ & $\begin{array}{r}1.05 \\
.21\end{array}$ & $\begin{array}{l}8.69 \\
1.33\end{array}$ & & & \\
\hline & & & & & & & & & & & \multicolumn{2}{|c|}{$\begin{array}{l}R^{2}=.26_{\mathrm{a}} \\
\text { Adjusted } R^{2}=.21 \\
R=.51^{* *}\end{array}$} & \\
\hline
\end{tabular}

Note-A unique variability, .11; shared variability, .15. AoA, objective age of acquisition; FAM, familiarity; IMAG, imageability; NSYL, number of syllables; NCONC, number of consonant clusters; NMRPH, number of morphemes; ETYM, etymology; DENS, phonological neighborhood density; STRS, stress; HFRQ, log of hypertext frequency; $S D$, standard deviation. ${ }^{*} p<.05 . \quad{ }^{* *} p<.01$.

Three of the nine independent variables contributed significantly to AoA: familiarity $\left(s r_{\mathrm{i}}^{2}=.11\right),(\log )$ hypertext frequency $\left(s r_{\mathrm{i}}^{2}<.01\right)$, and phonological neighborhood density $\left(s r_{i}^{2}=.01\right)$. These three variables combined contributed another $15 \%$ in shared variability. All together, $26 \%$ (and 21\% adjusted) of the variability in AoA was predicted by knowing the characteristics of a word on these three variables. Post hoc evaluations revealed that the correlations between AoA and the remaining six factors (imageability, number of syllables, number of consonant clusters, number of morphemes, etymology, and word stress) were not significant $(p>.05)$.

\section{Discussion}

The results of the multiple regression analyses revealed that a combination of phonological, lexical, morphological, and semantic factors contributes to the psycholinguistic construct of AoA. Specifically, of the 10 variables included as predictors of subjective AoA in the analysis, the combination of 8 explains approximately three quarters of the variance $\left(R^{2}=.76\right)$. That is, knowledge of concreteness, etymology, familiarity, frequency, imageability, number of phonemes, phonological neighborhood density, number of syllables, and the word's stress can allow for highly accurate estimates of AoA. For the objective AoA measures, the combination of 3 of the 10 variables - one semantic (familiarity), one phonological (phonological neighbor density), and one lexical (log hypertext frequency) - explained approximately one quarter of the variance $\left(R^{2}=.26\right)$. We attribute this difference between subjective and objective measures, for the most part, to the necessarily smaller word corpus used in the second analysis (150 vs. 1,351, used in the first analysis), rather than to a significant difference between subjective and objective measures. (We note that for the 150 words used in the second analysis, the correlation between subjective and objective AoA measures was highly significant.) On the other hand, the methodology for the construction of the Morrison et al. (1997) corpus may also explain the limited contribution of imageability and number of morphemes in the second analysis. In par- ticular, the objective AoA measures were collected from children's responses to pictures - stimuli that were by definition highly imageable and less morphemically complex; hence, less variable on those dimensions. Notwithstanding the satisfactory range for the imageability (463-652) and number of morphemes (1-2) in the objective AoA data set, this range was more limited than that observed for the subjective AoA corpus (210-643 for imageability, 1-4 for number of morphemes); this may account for the different significance of these factors between the two analyses. Nonetheless, the statistically significant predictors in both analyses parallel each other by reflecting the joint contribution of phonological, lexical, and semantic factors toward AoA. ${ }^{4}$ Therefore, neither an exclusively conceptualsemantic nor an exclusively phonological approach toward understanding AoA and AoA effects is appropriate. Instead, we argue that these analyses support hybrid models of noun acquisition.

Word learning requires the establishment of a durable link between an arbitrary word form and a concept, a mapping that requires semantic and phonological processes (de Saussure, 1916). A general framework for AoA that incorporates semantic and phonological constraints, therefore, has much potential to inform theories that posit exclusively formal or conceptual processes. Although independent main effects of phonology (e.g., word length, density) and semantics (e.g., concreteness, familiarity) are consistent with a hybrid account of AoA, the correlations obtained between semantic and phonological factors (see Table 1) are not predicted within contemporary theories of natural language premised on the relationship between form and meaning as being completely arbitrary (Glucksberg \& Danks, 1975). For example, the correlation between word concreteness and word length in syllables $(r=-.36)$ illustrates that concrete nouns tend to be shorter than abstract nouns (see also Reilly \& Kean, 2007; Reilly, Ramey, \& Milsark, 2004). The presence of a phonological-semantic relationship can potentially influence semantic fast mapping such that the effectiveness of a paired association may be moderated by the typicality 
of word form. Consider a hypothetical experimental paradigm in which researchers attempt to teach an infant at a particular age the novel verb glorping. If the infant fails to demonstrate knowledge of glorping, perhaps failing to look at the correct video depiction upon request, what would this indicate about his or her linguistic competency? Most would argue that there is insufficient demonstration of a particular requisite cognitive mechanism to acquire this verb at a particular stage of development. However, an alternative account is that form-meaning mapping is merely compromised by a phonologically improbable target word. Lexical acquisition paradigms that rely solely on semantic explanations often lack the sensitivity to evaluate possibilities that consider multivariate explanations to psycholinguistic variables such as AoA.

The present study used multiple regression analyses of open-source databases and revealed that several psycholinguistic factors in combination contribute to a word's age of acquisition. Approaches to lexical acquisition that rely solely on phonological or conceptual-semantic variables and do not take into account the rich relations among phonological, lexical, morphological, and semantic factors are, thus, limited in scope. Because our methodology involved only linguistic databases, it did not take into account the developmental contributions to word learning of theory of mind, intentionality, or other individual learning differences. We were also limited by using only English nouns. Future research should examine the phonological, lexical, morphological, and semantic factors that contribute to AoA in other languages, as well as correlate these diachronic accomplishments with other social-cognitive factors that address more globally the factors of lexical acquisition. We argue that the present analyses provide initial support for a hybrid account of English noun acquisition that involves phonological, lexical, and semantic factors.

\section{AUTHOR NOTE}

Portions of this work were supported by a postdoctoral training grant, NIH/NRSA AG00255, awarded to the first author from the National Institute of Aging. The authors thank Shaleigh Kwok for her help in coding parts of the noun database. Correspondence concerning this article should be addressed to J. Reilly, Departments of Communicative Disorders and Neurology, University of Florida, P.O. Box 100174, Gainesville, FL 32610 (e-mail: jjreilly@phhp.ufl.edu).

\section{REFERENCES}

Aslin, R. N., Saffran, J. R., \& Newport, E. L. (1998). Computation of conditional probability statistics by 8 -month-old infants. Psychological Science, 9, 321-324.

Balota, D. A., Cortese, M. J., Sergent-Marshall, S. D., Spieler, D. H., \& YAP, M. J. (2004). Visual word recognition of single-syllable words. Journal of Experimental Psychology: General, 133, 283-316.

Balota, D. A., Pilotti, M., \& Cortese, M. J. (2001). Subjective frequency estimates for 2,938 monosyllabic words. Memory \& Cognition, 29, 639-647.

Balota, D. A., Yap, M. J., Cortese, M. J., Hutchison, K. A., KessLER, B., LofTIS, B., ET AL. (2007). The English lexicon project. Behavior Research Methods, 39, 445-459.

Barca, L., Burani, C., \& Arduino, L. S. (2002). Word naming times and psycholinguistic norms for Italian nouns. Behavior Research Methods, Instruments, \& Computers, 34, 424-434.

Bird, H., Franklin, S., \& Howard, D. (2001). Age of acquisition and imageability ratings for a large set of words, including verbs and func- tion words. Behavior Research Methods, Instruments, \& Computers, 33, 73-79.

Bloom, L., Margulis, C., Tinker, E., \& Fujita, N. (1996). Early conversations and word learning: Contributions from child and adult. Child Development, 67, 3154-3175.

Brown, G. D., \& WATSON, F. L. (1987). First in, first out: Word learning age and spoken word frequency as predictors of word familiarity and word naming latency. Memory \& Cognition, 15, 208-216.

Brown, R. W. (1976). A first language: The early stages. Harmondsworth, MA: Penguin.

Brysbaert, M., Lange, M., \& Van Wijnendaele, I. (2000). The effects of age-of-acquisition and frequency of occurrence in visual word recognition: Further evidence from the Dutch language. European Journal of Cognitive Psychology, 12, 65-85.

Coltheart, M. (1981). The MRC psycholinguistic database. Quarterly Journal of Experimental Psychology, 33A, 497-505.

De Saussure, F. (1916). A course in general linguistics (C. Bally \& A. Sechehaye, Eds.). New York: McGraw-Hill.

FunNell, E., Hughes, D., \& Woodcock, J. (2006). Age of acquisition for naming and knowing: A new hypothesis. Quarterly Journal of Experimental Psychology, 59, 268-295.

GENTNER, D. (1982). Why nouns are learned before verbs: Linguistic relativity versus natural partitioning. In S. A. Kuczaj, II (Ed.), Language development (Vol. 2, pp. 301-334). Hillsdale, NJ: Erlbaum.

Gilhooly, K. J., \& LogIE, R. H. (1980). Age-of-acquisition, imagery, concreteness, familiarity, and ambiguity measures for 1,944 words. Behavior Research Methods \& Instrumentation, 12, 395-427.

GlucksBerg, S., \& DANKs, J. H. (1975). Experimental psycholinguistics. Hillsdale, NJ: Erlbaum.

Jescheniak, J. D., \& LeVelt, W. J. (1994). Word frequency effects in speech production: Retrieval of syntactic information and of phonological form. Journal of Experimental Psychology: Learning, Memory, \& Cognition, 20, 824-843.

Juhasz, B. J. (2005). Age-of-acquisition effects in word and picture identification. Psychological Bulletin, 131, 684-712.

JusczyK, P. W., Luce, P. A., \& Charles-Luce, J. (1994). Infants' sensitivity to phonotactic patterns in the native language. Journal of Memory \& Language, 33, 630-645.

KuČERA, H., \& FrANCIS, W. N. (1982). Computational analysis of presentday American English. Providence, RI: Brown University Press.

Luce, P. A., \& Pisoni, D. B. (1998). Recognizing spoken words: The neighborhood activation model. Ear \& Hearing, 19, 1-36.

LunD, K., \& Burgess, C. (1996). Producing high-dimensional semantic spaces from lexical co-occurrence. Behavior Research Methods, Instruments, \& Computers, 28, 203-208.

Morrison, C. M., Chappell, T. D., \& Ellis, A. W. (1997). Age of acquisition norms for a large set of object names and their relation to adult estimates and other variables. Quarterly Journal of Experimental Psychology, 50A, 528-559.

Morrison, C. M., \& Ellis, A. W. (2000). Real age of acquisition effects in word naming and lexical decision. British Journal of Psychology, 91, 167-180.

Morrison, C. M., Hirsh, K. W., Chappell, T., \& Ellis, A. W. (2002). Age and age of acquisition: An evaluation of the cumulative frequency hypothesis. European Journal of Cognitive Psychology, 14, 435-459.

NeLSON, D. L., \& SCHREIBER, T. A. (1992). Word concreteness and word structure as independent determinants of recall. Journal of Memory \& Language, 31, 237-260.

Paivio, A. (1986). Mental representations: A dual coding approach. New York: Oxford University Press.

Paivio, A., Yuille, J. C., \& Madigan, S. A. (1968). Concreteness, imagery, and meaningfulness values for 925 nouns. Journal of Experimental Psychology, 76(Suppl.), 1-25.

Reilly, J., \& KeAN, J. (2007). Morphophonological distinctiveness of high- and low-imageability nouns: Analyses and implications for psycholinguistic research. Cognitive Science, 31, 157-168.

Reilly, J., Ramey, C. H., \& Milsark, G. (2004). Confounds in the distinction between high and low imageability words: Phonological, etymological, and morphological differences. Brain \& Language, 91, $147-149$.

Simpson, J. A., \& Weiner, E. S. C. (Eds.) (1989). Oxford English dictionary (2nd ed.). Oxford: Oxford University Press. Online version retrieved July 2, 2004, from dictionary.oed.com/cgi/entry/00181778. 
Steyvers, M., \& Tenenbaum, J. B. (2005). The large-scale structure of semantic networks: Statistical analyses and a model of semantic growth. Cognitive Science, 29, 41-78.

TABACHNicK, B. G., \& Fidell, L. S. (2001). Using multivariate statistics (4th ed.). Needham Heights, MA: Allyn \& Bacon.

Toglia, M. P., \& Battig, W. R. (1978). Handbook of semantic word norms. New York: Erlbaum.

ZeVIn, J., \& SeIDENBERG, M. S. (2002). Age of acquisition effects in word reading and other tasks. Journal of Memory \& Language, 47, 1-29.

\section{NOTES}

1. An active debate persists as to whether AoA is a valid psycholinguistic construct or a simple artifact of word frequency (Balota, Cortese, Sergent-Marshall, Spieler, \& Yap, 2004; Zevin \& Seidenberg, 2002). According to Juhasz's recent (2005) review of over 140 studies on AoA, however, it does appear to be a measure that is not coextensive with word frequency.

2. The results of the correlational analyses along with the noun corpus are freely available to other researchers by contacting the corresponding author.

3 . The evaluation of the assumptions required for a multiple regression analysis was performed according to the guidelines provided by
Tabachnick and Fidell (2001, pp. 56-110). Particularly with respect to the assumptions of singularity and multicollinearity, squared multiple correlations (SMC) were calculated for each variable and converted to tolerances $(1-\mathrm{SMC})$. None of the tolerances approached zero, hence satisfying the singularity and multicollinearity assumptions. Additionally, all variables entered the regression equation without violating the default value for tolerance, which further resolved doubts about possible multicollinearity and singularity among the independent variables. Finally, the highest correlations among the variables do not exceed $r=.67$, which further supports the conclusion that the multivariate assumptions were adequately satisfied.

4. We note that in the present analyses, we consider familiarity as a primarily semantic variable. In particular, according to previous research (e.g., Balota, Pilotti, \& Cortese, 2001), familiarity is strongly correlated with semantic attributes of the words. For example, a measure of meaningfulness (i.e., an index of a word's semantic associations with other words) has been shown to be the best predictor of subjective familiarity scores $(r=.82$; see also Toglia \& Battig, 1978).

(Manuscript received May 18, 2006;

revision accepted for publication February 20, 2007.) 